\title{
TRENDS IN PARENT-ADOLESCENT COMMUNICATION IN THE CZECH REPUBLIC BETWEEN 2002 AND 2014: RESULTS OF THE HBSC STUDY
}

\author{
Jana Vokáčová1, Jana Vašičková1, Lenka Hodačová2, Zuzana Půžová3 , Izabela Tabak ${ }^{4}$ \\ 'Department of Social Sciences in Kinanthropology, Faculty of Physical Culture, Palacký University Olomouc, Olomouc, Czech Republic \\ 2Department of Social Medicine, Faculty of Medicine in Hradec Králové, Charles University, Hradec Králové, Czech Republic \\ ${ }^{3}$ Institute of Active Lifestyle, Faculty of Physical Culture, Palacký University Olomouc, Olomouc, Czech Republic \\ ${ }^{4}$ Department of Child and Adolescent Health, Institute of Mother and Child, Warsaw, Poland
}

\section{SUMMARY}

Objective: Good parent-child communication is associated with adolescent well-being. The aim of the present study was to report time trends in parent-adolescent communication in biological and stepfamilies in the Czech Republic between 2002 and 2014 and to assess gender and age differences.

Methods: The research sample consisted of 16,160 adolescents aged 11,13 , and 15 years ( $48.1 \%$ of boys) who participated in the 2002, 2006, 2010 and 2014 surveys within the Health Behaviour in School-aged Children (HBSC) study in the Czech Republic. The trends in family communication were evaluated using logistic regression.

Results: Compared with 2002, a significant increase in the ease of communication with biological parents was observed in 2014. On the other hand, the adolescents' perception of communication with stepparents did not change in this period. Compared with the girls, a higher rate of boys reported communication with their father or stepfather as being easy throughout the study period. The ease of talking to biological parents decreased with age.

Conclusion: The growing positive trend demonstrated an improvement in communication in intact families at the beginning of the 21 st century, while communication with stepparents remained unchanged from 2002 to 2014 . The increase in rates of ease of communication with biological fathers was reported by both genders. However, the ease of talking to biological mothers grew mainly among boys.

Key words: adolescents, trends, communication, parents, stepparents, HBSC study

Address for correspondence: J. Vokáčová, Department of Social Sciences in Kinanthropology, Faculty of Physical Culture, Palacký University Olomouc, trída Míru 117, 771 11, Olomouc, Czech Republic. E-mail: jana.vokacova@upol.cz

https://doi.org/10.21101/cejph.a4952

\section{INTRODUCTION}

Parent-adolescent Communication and Health Benefits

The ease of communication between parents and their child is an indicator of family bonding (1). It is one of the key ways in which the family can act as a protective health factor and promote pro-social values during the development of the child (2).

Research evidence shows that easy communication with parents has several health benefits for children. Moreno et al. (3) pointed out that children who considered talking to their parents to be easy also often rated their health positively, mentioned fewer psychological complaints, and reported greater life satisfaction. Moreover, the findings underlined the protective role of parentchild communication patterns in potential substance use (4). Easy communication is associated with lower rates of smoking (5), alcohol drinking $(6,7)$, and cannabis use (8) among adolescents.

\section{Developmental Changes}

In adolescence a desire to be independent leads to lower willingness to share information with parents and communication becomes generally more difficult for both sides (9-11). In early adolescence an increase in closure and secrecy is typical, as is a decrease in parental solicitation (12). At the same time parents reduce their level of control and their knowledge about adolescents' leisure time activities naturally decreases (12). However, recent studies have shown that these autonomyrelated processes in parent-child relationships can be important for the recovery of parent-adolescent communication in later adolescence $(12,13)$. Excessive interference in adolescent needs for autonomy may complicate the process of communication. To maintain easy parent-adolescent communication, experts recommend to respect developmental changes in adolescents and communication based on mental support, discussion and negotiation (14). 


\section{Intact vs. Step Family}

The ease of parent-adolescent communication depends on many factors. Among these, the family structure and the child's age and gender are frequently discussed (15). Since the 1990s we have been able to observe a rising rate of divorces leading to more single-parent and stepparent households $(16,17)$. Many research studies have shown that these changes in the composition of the family are critical to children's well-being and development $(17,18)$. Hetherington and Kelly (19) mentioned a 5-to-7-year period of destabilization and elevated stress after a stepfamily forms. Adolescents who live with a stepparent are more likely to report various health complaints, e.g. depression $(20,21)$ and lower life satisfaction (22), compared with those living with both biological parents.

On the other hand, living with a stepparent might be associated with better physical health and some behavioural outcomes than in a single-parent family (17). The majority of stepfamilies involve a residential stepfather (23), with whom the stepchild has to cope with the situation that they should form a satisfying relationship. According to King et al. (24), most adolescents reported having a good relationship with their stepfather, but many of them perceived weak closeness (43\%), low warmth on the part of the stepfather (31\%), and dissatisfaction with communication (30\%). Different studies proved that open and regular communication (25-27), as well as shared interests (28), can help to develop closer relationships between a stepparent and stepchild.

\section{Gender and Age Differences}

The perception of parent-adolescent communication varies according to the gender of both children and parents. Among adolescents, the mother rather than the father is perceived as understanding and communication with her is easier $(14,29)$. Especially girls tend to experience more difficulties in talking with their fathers, both biological and stepfathers $(24,30)$. This may be associated with the overall higher frequency and quality of time spent by boys with their family, especially with their fathers $(16,31)$. Girls, in contrast, experience greater limitations on their freedom and higher levels of parental monitoring $(16,32)$.

Given the age differences, the study of Keijsers and Poulin (12) showed that changes in parent-child communication took place throughout adolescence. Older adolescents are more likely to find difficulties in communication with their parents than their younger counterparts $(14,15)$. However, these patterns of communication separation are understandable and they might even lead to the recovery of closeness in the future (12).

\section{Research Aim}

To reach an everyday work-life balance and maintain a functional family is one of the biggest challenges in contemporary families. It has been proposed that good family communication may have direct effects on the functioning of the family and children's health $(3,15,33)$. However, little is known about how communication changes over time in relation to new family structures. Given the large number of children living in stepfamilies, it is also important to understand how adolescents perceive communication with their non-biological parents over time. The current study builds upon recent research on factors that are associated with adolescents' communication in intact and stepfamilies $(12,15,17)$ and extends the knowledge about changes in parent-adolescent communication at the beginning of the new millennium $(14,34)$. It examines the secular trend in the perceived ease of parent-adolescent communication within a large and representative adolescent population. The main aim of the present paper is to report time trends in parent-adolescent communication in biological and stepfamilies between the years 2002 and 2014 in the Czech Republic and to assess gender and age differences.

\section{MATERIALS AND METHODS}

\section{Sample and Procedure}

The present paper is based on the Health Behaviour in Schoolaged Children (HBSC) study. It is a cross-sectional study, carried out in collaboration with the WHO (30). The study focused on health and its socioeconomic determinants in 11-, 13-, and 15-year-old adolescents in Europe and North America.

The data presented here come from four consecutive surveys conducted in the Czech Republic in 2002, 2006, 2010 and 2014, according to the HBSC methodology. Throughout all the four waves of data collection, the schools to be addressed were stratified by region and the ratio of primary vs. secondary schools and then randomly selected in order to obtain nationally representative samples. Since 2002 the response rate at the school level has not dropped below $90 \%$.

At each school one class per grade was selected at random from the fifth, seventh, and ninth grades, which are in general attended by children aged 11, 13, and 15 years, respectively. The questionnaires were distributed by trained administrators and the pupils had one school lesson (45 minutes) to complete them. The overall response rate has never dropped below $87 \%$.

After merging the datasets from the respective survey years, which had been previously inspected and cleaned by the HBSC Data Bank at the University of Bergen, Norway, we selected only the 11-, 13-, and 15-year-olds, as prescribed by the HBSC research protocol. Then, after the participants with missing data on all the parent-adolescent communication items had been excluded $(n=463)$, the final sample consisted of 16,160 adolescents. The sample characteristics are presented in Table 1.

Participation in all four surveys was voluntary, anonymous, and without any incentives offered to the respondents. The present time trend study was approved by the Ethics Committee of the Faculty of Physical Culture, Palacký University Olomouc (No. 57/2014).

\section{Measures}

The family communication was measured using the following question: "How easy is it for you to talk to the following persons about things that really bother you?" $(14,35,36)$. The checklist of close persons included father, stepfather (or mother's boyfriend), mother, and stepmother (or father's girlfriend) with the response options of very easy, easy, difficult, very difficult, and don't have or see this person.

The items were dichotomized as easy (very easy/easy) vs. difficult (difficult/very difficult) $(14,35,36)$. The option "don't have or see this person" was considered a missing value. 
Table 1. Sample characteristics (\%) (total sample $N=16,160)$

\begin{tabular}{|c|c|c|c|c|c|}
\hline \multirow{2}{*}{\multicolumn{2}{|c|}{ Variables }} & \multicolumn{4}{|c|}{ Year of survey } \\
\hline & & \multirow{2}{*}{$\begin{array}{c}\begin{array}{c}2002 \\
N=3,924\end{array} \\
46.7\end{array}$} & \multirow{2}{*}{$\begin{array}{c}\begin{array}{c}2006 \\
N=4,045\end{array} \\
50.2\end{array}$} & \multirow{2}{*}{$\begin{array}{c}2010 \\
\mathrm{~N}=3,851\end{array}$} & \multirow{2}{*}{$\begin{array}{c}\begin{array}{c}2014 \\
\mathrm{~N}=4,340\end{array} \\
48.5\end{array}$} \\
\hline Condor & Boys & & & & \\
\hline Gerluel & Girls & 53.3 & 49.8 & 52.9 & 51.5 \\
\hline \multirow{3}{*}{ Age } & 11 years & 33.8 & 31.4 & 32.1 & 31.1 \\
\hline & 13 years & 32.7 & 33.7 & 33.2 & 33.9 \\
\hline & 15 years & 33.5 & 34.9 & 34.7 & 35.0 \\
\hline \multirow{4}{*}{$\begin{array}{l}\text { Rate of valid responses } \\
\text { per variable of interest* }\end{array}$} & Communication with biological father & 89.7 & 91.4 & 91.5 & 91.0 \\
\hline & Communication with biological mother & 97.4 & 95.8 & 95.2 & 97.7 \\
\hline & Communication with stepfather & 12.7 & 15.6 & 20.6 & 20.0 \\
\hline & Communication with stepmother & 5.7 & 8.7 & 15.1 & 13.8 \\
\hline
\end{tabular}

*the response category 'don't have or see this person' was considered to be 'invalid' for the purpose of the analyses

\section{Statistical Analyses}

First, we described the demographic characteristics of the study population. Next, the prevalence rates of adolescents who perceived communication in the family as being easy in the respective survey years were computed for the entire sample, as well as for the sample stratified by gender and age. To assess the statistical significance of the changes in family communication between the first and the last survey and the pairs of consecutive surveys and also the differences between gender and age categories in respective survey years, we used Pearson's chi-squared test. The 2002-2014 trends in family communication were evaluated by logistic regression using the enter method. First, we assessed the crude odds ratios, then we adjusted for gender and age. All the statistical analyses were performed using the IBM SPSS 22.0 for Windows (IBM Corp. Released 2013).

\section{RESULTS}

Figure 1 shows the time trends in parent-adolescent communication in the period 2002-2014. Compared to 2002, adolescents in 2014 report very easy or easy communication with their biological parents more often. Between 2002 and 2014, there was a linear increase in the number of adolescents reporting that it was easy to talk to their biological mother and father. In this period, the rate of adolescents perceiving communication with their biological father as being easy grew from $57 \%$ to $67 \%(\mathrm{p}<0.001)$ and from $77 \%$ to $84 \%(p<0.001)$ with regard to easy communication with their biological mother. Concerning communication with stepparents, we observed no statistically significant changes when comparing the data from 2002 to 2014 . The percentage of adolescents reporting that it was easy to talk with their stepmother or stepfather remained quite stable during the research period.

The prevalence rates of the sample stratified by gender and age are presented in Table 2. Talking to the biological father was perceived as easy or very easy significantly more often among the boys throughout all the four waves of data collection. We observed the biggest gender-specific differences in communication with the biological father. The rate of boys reporting it as being easy was higher by $14-18 \%$ than among the girls $(\mathrm{p}<0.001)$ in all the survey years.
The perception of easy communication with the biological mother did not vary according to gender as much as in the case of communication with the biological father. In 2002, the girls, compared to the boys, experienced communication with their biological mother as being slightly easier $(\mathrm{p}<0.05)$. No statistically significant differences between the genders were then observed in the 2006 and 2010 survey years. However, in 2014 the boys indicated that they could communicate more easily with their biological mothers $(p<0.05)$. Moreover, the ease of the boys' communication with their biological mother increased by $10 \%$ when 2002 and 2014 were compared, which was 2.5 times more than among the girls.

Statistically significant gender differences were also found in communication with stepparents. Except for 2002, in the remaining three surveys statistically higher numbers of boys than girls reported that talking to their stepfather was easy $(p<0.001)$. In the 2014 survey $57 \%$ of the boys reported that communication with their stepfather was easy but among the girls it was only $43 \%$. Regarding the ease of communication with stepmothers, we did not find the gender differences to be statistically significant.

The age-specific trends actually matched the overall trends in parent-adolescent communication quite closely (Table 2). The largest numbers of adolescents reported that communication with their parents was easy at 11 years, and, in general, the rate

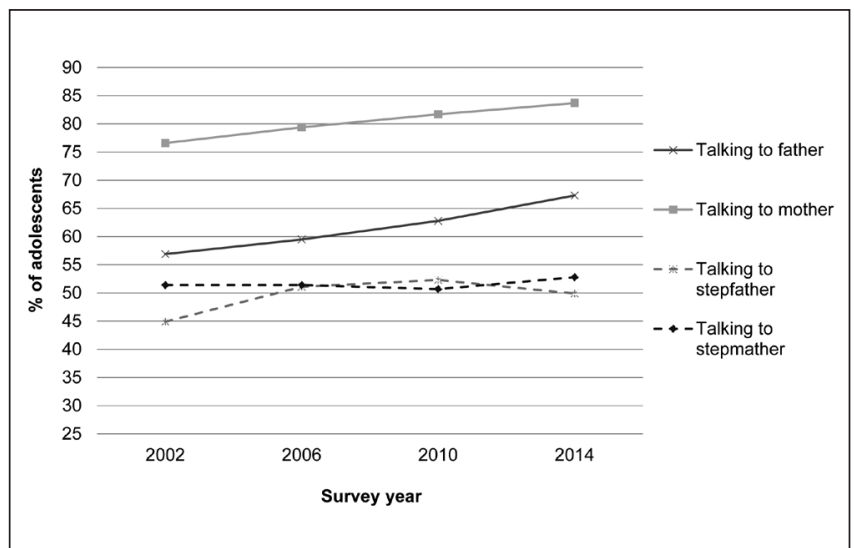

Fig. 1. Trends in easy/very easy parent-adolescent communication. 
decreased with increasing age. Significant age-specific differences were observed in ease of communication with the biological father, where the relative frequencies differed by $10-16 \%$ between the 11 - and 15 -year-olds $(\mathrm{p}<0.001)$ throughout the present study period. Communication with the biological mother was also easier for the 11-year-old adolescents than for those aged 15 (2002 and $2006, \mathrm{p}<0.01 ; 2010$ and 2014, $\mathrm{p}<0.001$ ), but with smaller relative frequencies, the differences ranging between 7.5 and $10 \%$. Across all ages consistent positive trends in communication with biological parents were identified. The ease of communication with stepparents did not yield such clear results regarding the age categories. A significant difference between the boys and girls between the ages of 11 and 15 was found in talking with their stepfather, however, only in the two last survey years, $2010(\mathrm{p}<0.01)$ and $2014(p<0.05)$. The age differences were not significant for the perception of communication with stepmothers (Table 2).

To assess the overall change in parent-adolescent communication in the 2002-2014 period logistic regression was used. First, we estimated the crude odds ratios for change in communication with the biological father (OR 1.55; 95\% CI 1.41-1.71) and biological mother (OR 1.57; 95\% CI 1.41-1.76) between 2002, as a reference category, and 2014. Then we adjusted the analyses for age category and gender. Compared to 2002, the adolescents in the 2014 survey were 1.58 times more likely to communicate easily with their biological fathers $(95 \%$ CI $1.44-1.74)$ and 1.59 times with their biological mothers (95\% CI 1.42-1.78), respectively.
The changes observed in communication between stepparents and adolescents in the period 2002-2014 were not statistically significant, either in crude terms or after adjustment for age and gender.

\section{DISCUSSION}

The present study examines time trends in parent-adolescent communication in the Czech Republic between 2002 and 2014. Currently, boys and girls evaluate their communication with their biological parents more positively than twelve years ago. While the ease of communication in intact families grew, adolescents' conversation with stepparents about troubling matters remained almost unchanged.

Like some of the latest trend studies $(14,34)$, we found that nowadays adolescents perceive communication with their biological parents more positively than in the past. Tabak et al. (14), who examined changes in family communication in 16 countries, mentioned that difficulties in child-parent communication decreased from 1993 to 2002 and, moreover, in some countries this positive trend continued in 2006. Another recent study (34) confirmed that there were positive changes in terms of the ease of talking to biological mothers and fathers in most European countries until 2010. Our results are in line with these conclusions and indicate the long-term growing trend in the quality of communication with biological parents.

Table 2. Trends in parent-adolescent communication by gender and age

\begin{tabular}{|c|c|c|c|c|c|c|c|c|c|c|c|c|c|}
\hline \multirow[t]{2}{*}{ Group } & \multirow[t]{2}{*}{ Survey } & \multicolumn{3}{|c|}{$\begin{array}{l}\text { Talking to father } \\
\text { (very easy or easy) }\end{array}$} & \multicolumn{3}{|c|}{$\begin{array}{l}\text { Talking to stepfather } \\
\text { (very easy or easy) }\end{array}$} & \multicolumn{3}{|c|}{$\begin{array}{l}\text { Talking to mother } \\
\text { (very easy or easy) }\end{array}$} & \multicolumn{3}{|c|}{$\begin{array}{l}\text { Talking to stepmother } \\
\text { (very easy or easy) }\end{array}$} \\
\hline & & $\%$ & Trend & $p$ & $\%$ & Trend & $p$ & $\%$ & Trend & $p$ & $\%$ & Trend & $p$ \\
\hline \multirow{4}{*}{ Boys } & 2014 & 74.7 & $\uparrow$ & $* *$ & 57.4 & & ns & 85.2 & $\uparrow$ & $* * *$ & 56.4 & & $\mathrm{~ns}$ \\
\hline & 2010 & 70.6 & & ns & 59.6 & & ns & 81.0 & & ns & 52.2 & & $\mathrm{~ns}$ \\
\hline & 2006 & 68.6 & $\bar{\uparrow}$ & ** & 60.1 & $\uparrow$ & * & 79.1 & $\uparrow$ & ** & 52.2 & & $\mathrm{~ns}$ \\
\hline & 2002 & 64.4 & & ns & 49.6 & & ns & 75.0 & & ns & 56.0 & & $\mathrm{~ns}$ \\
\hline \multirow{4}{*}{ Girls } & 2014 & 60.1 & $\uparrow$ & $* *$ & 43.0 & & ns & 82.3 & & ns & 49.4 & & $\mathrm{~ns}$ \\
\hline & 2010 & 55.6 & $\uparrow$ & $* *$ & 45.8 & & ns & 82.3 & $\uparrow$ & * & 49.4 & & $\mathrm{~ns}$ \\
\hline & 2006 & 50.2 & & ns & 42.9 & & ns & 79.7 & & ns & 50.8 & & $\mathrm{~ns}$ \\
\hline & 2002 & 50.2 & & ns & 41.1 & & ns & 78.0 & & ns & 46.3 & & ns \\
\hline \multirow{4}{*}{11 years } & 2014 & 76.2 & $\bar{\uparrow}$ & ** & 52.1 & & ns & 87.4 & & ns & 51.7 & & $\mathrm{~ns}$ \\
\hline & 2010 & 70.6 & $\uparrow$ & ** & 60.5 & & ns & 86.6 & $\uparrow$ & ** & 53.0 & & ns \\
\hline & 2006 & 65.5 & & ns & 55.2 & & ns & 81.9 & & ns & 49.5 & & $\mathrm{~ns}$ \\
\hline & 2002 & 63.5 & & ns & 48.4 & & ns & 79.8 & & ns & 50.0 & & $\mathrm{~ns}$ \\
\hline \multirow{4}{*}{13 years } & 2014 & 65.4 & & ns & 54.0 & & ns & 82.8 & & ns & 55.2 & & $\mathrm{~ns}$ \\
\hline & 2010 & 62.2 & $\uparrow$ & * & 49.6 & & ns & 81.5 & & ns & 49.2 & & $\mathrm{~ns}$ \\
\hline & 2006 & 57.5 & & ns & 53.2 & $\uparrow$ & $* *$ & 79.9 & $\uparrow$ & * & 52.8 & & ns \\
\hline & 2002 & 56.0 & & ns & 39.3 & & ns & 75.2 & & ns & 56.0 & & $\mathrm{~ns}$ \\
\hline \multirow{4}{*}{15 years } & 2014 & 60.9 & $\uparrow$ & * & 44.2 & & ns & 81.4 & $\uparrow$ & * & 51.2 & & ns \\
\hline & 2010 & 56.0 & & ns & 48.1 & & $\mathrm{~ns}$ & 77.5 & & ns & 50.2 & & ns \\
\hline & 2006 & 56.0 & $\bar{\uparrow}$ & * & 45.4 & & ns & 76.7 & & ns & 51.6 & & ns \\
\hline & 2002 & 51.3 & & ns & 47.2 & & $\mathrm{~ns}$ & 74.7 & & ns & 48.0 & & ns \\
\hline
\end{tabular}

$\uparrow$ indicates a statistically significant $\left({ }^{*} p<0.05,{ }^{* *} p<0.01,{ }^{* *} p<0.001\right)$ increase between two consecutive surveys (e.g. 2002 and 2006 ) per population group; ns indicates not significant; statistical significance was calculated by means of Pearson's chi-squared test. 
In spite of high divorce rates and the tendency of parents to form new partnerships or remarriages (17), recent surveys have not aimed at monitoring trends in communication in non-intact families. Our analysis demonstrated that adolescents' perception of communication with their stepparents did not change significantly between 2002 and 2014. However, this finding may be partly attributable to a lack of more detailed information on stepparents. The limitations of our data preclude an examination of important stepparent-adolescent communication factors which, according to experts, have an influence on the whole process of the stepparentchild relationship (37). For example, when becoming a stepfather and being able to establish a close and satisfying relationship with an adolescent stepchild, the first year is the most important (24), together with the quality of the mother-child relationship.

Consistently with previous research (15), our results showed that adolescent's gender plays an important role in their perception of the ease of talking with their parents about things that bother teenagers. Compared with the girls, boys reported positive communication with their biological and stepfathers more frequently. These findings are similar to the recent results of an international study (30), in which boys in 42 European and North American countries were more likely to perceive communication with their biological fathers as being easy than girls were. The gender difference was greater than $15 \%$ in almost all the countries at the ages of 13 and 15, which corresponds to our results. In respect to communication with stepfathers, our findings are in line with several studies $(37,38)$ in which the girls felt a lower level of closeness to their stepfathers than the boys did.

In spite of gender differences in the quality of communication, we found that the rates of both boys and girls reporting easy communication with their fathers tended to grow in the period 2002-2014. A similar trend was found among adolescents in a recent international trend study (34) where in 2010 boys and girls were two times more likely to be able to communicate easily with their biological father than in 2002. In our research, communication with mothers was assessed as easy more often than communication with fathers. The results did not show gender differences, but the positive growing trend was higher in the boys than in the girls. Similar concern over a shift in the character of communication with mothers was identified among European and North American adolescents, where a significant positive trend was observed just for boys (34). Further research that focuses on unveiling the causes of this phenomenon is warranted.

The global phenomenon of the decreasing frequency of ease of communication in intact families with adolescents' increasing age $(15,30)$ was also confirmed by our study, as we observed a similar pattern of less frequent ease of communication with biological parents in older children throughout all the four surveys. According to Keijsers and Poulin (12), escalating psychological separation from parents in adolescents is accompanied by changes in communication patterns and can cause high levels of secrecy and less willingness to talk about things that bother adolescents. Moreover, the frequency of joint family activities also decreases at older age $(31,39)$, which can reduce family bonding time.

Communication in stepfamilies did not show clear results throughout the age categories. No effect of age on stepfather-child relationships was observed in the study of King et al. (24). On the other hand, some previous research found that older adolescents reported weaker ties with their stepfathers than younger ones did
(38). Ganong et al. (28) explain that the stepparent-adolescent relationship is influenced by the age of children when the relationship began. Children living with a stepparent from infancy tend to accept their stepfather or stepmother as another parent more naturally, whereas older children tend to assess the stepparent more critically. They build a good relationship on the basis of evaluation of resources brought to the family by the stepparent, his/her treatment of the biological parent, and the nature of his/ her attempts to establish discipline and friendship. However, in our study such information was not included. Unclear conclusions should be clarified in future research.

\section{Strengths and Limitations}

The important strengths of the present study lie in the size and representativeness of the sample of adolescents. Moreover, the study uses the well-established HBSC methodology and the same survey procedure every four years, which facilitates trend analyses.

Our findings also need to be interpreted in the light of some limitations. First, all the analyses were based on self-reported data, which is more susceptible to recall bias, though the measures in general have been well validated (40). Second, we note that our findings report cross-sectional trends and may not reflect longitudinal trends over time. Moreover, we did not examine other demographic variables (e.g. income, living area, family size) and nor did we have access to information on how long the stepfather or stepmother had been living in the particular family, which may affect the level of parent-adolescent communication.

\section{CONCLUSION}

In general, the ease of communication between biological parents and adolescents in the Czech Republic tended to grow between 2002 and 2014. In particular, we observed an increase in the ease of talking to fathers about troubling things in both genders. Moreover, the boys also frequently reported that talking to their mother was easy in recent times. On the other hand, contemporary adolescents' perception of the ease of communication with stepparents did not change in comparison with 2002.

We believe that our results provide important knowledge about the direction of family communication at the beginning of the 21 st century. Future research should concentrate on trends in parent-adolescent communication related to problematic themes, which might be more difficult for children to talk about (e.g. risk behaviours - tobacco use, alcohol use, sexual behaviour, fighting, bullying etc).

It should also focus on the trends in associations between the quality of family communication, social support in the family, and adolescents' health behaviours.

\section{Acknowledgement}

This work was supported by the Czech Ministry of Education, Youth, and Sports (MEYS) under Contract No. LG14042 and No. LG14043 and by the research grant of the Czech Science Foundation No. GA 17-12579S.

\section{Conflict of Interests}

None declared 


\section{REFERENCES}

1. Laursen B. Conflict and social interaction in adolescent relationships. J Res Adolesc. 1995;5(1):55-70.

2. Currie C, Zanotti C, Morgan A, Currie D, de Looze M, Roberts C, et al., editors. Social determinants of health and well-being among young people. Health Behaviour in School-aged Children (HBSC) study: international report from the 2009/2010 survey. Copenhagen: WHO Regional Office for Europe; 2012.

3. Moreno C, Sánchez-Queija I, Muñoz-Tinoco V, de Matos MG, Dallago L, Bogt TT, et al.; HBSC Peer Culture Focus Group. Cross-national associations between parent and peer communication and psychological complaints. Int J Public Health. 2009 Sep;54 Suppl 2:235-42.

4. Kuntsche EN, Silbereisen RK. Parental closeness and adolescent substance use in single and two-parent families in Switzerland. Swiss J Psychol. 2004;63(2):85-92.

5. Pokhrel P, Unger JB, Wagner KD, Ritt-Olson A, Sussman S. Effects of parental monitoring, parent-child communication, and parents' expectation of the child's acculturation on the substance use behaviors of urban, Hispanic adolescents. J Ethn Subst Abuse. 2008;7(2):200-13.

6. Tomčíková Z, Veselská ZD, Madarasová Gecková A, van Dijk JP, Reijneveld SA. Adolescents' drinking and drunkenness more likely in one-parent families and due to poor communication with mother. Cent Eur J Public Health. 2015 Mar;23(1):54-8.

7. Zambon A, Lemma P, Borraccino A, Dalmasso P, Cavallo F. Socioeconomic position and adolescents' health in Italy: the role of the quality of social relations. Eur J Public Health. 2006 Dec;16(6):627-32.

8. Luk JW, Farhat T, Iannotti RJ, Simons-Morton BG. Parent-child communication and substance use among adolescents: do father and mother communication play a different role for sons and daughters? Addict Behav. 2010 May;35(5):426-31.

9. Keijsers L, Branje SJ, Frijns T, Finkenauer C, Meeus W. Gender differences in keeping secrets from parents in adolescence. Dev Psychol. 2010 Jan;46(1):293-8.

10. Laird RD, Marrero MD, Melching JA, Kuhn ES. Information management strategies in early adolescence: developmental change in use and transactional associations with psychological adjustment. Dev Psychol. 2013 May;49(5):928-37.

11. Masche JG. Explanation of normative declines in parents' knowledge about their adolescent children. J Adolesc. 2010 Apr;33(2):271-84.

12. Keijsers L, Poulin F. Developmental changes in parent-child communication throughout adolescence. Dev Psychol. 2013 Dec;49(12):2301-8.

13. Koepke S, Denissen JJA. Dynamics of identity development and separation-individuation in parent-child relationships during adolescence and emerging adulthood - a conceptual integration. Dev Rev. 2012;32(1):6788.

14. Tabak I, Mazur J, Granado Alcón MDC, Örkenyi Á, Zaborskis A, Aasvee $\mathrm{K}$, et al. Examining trends in parent-child communication in Europe over 12 years. J Early Adolesc. 2012;32(1):26-54.

15. Levin KA, Dallago L, Currie C. The association between adolescent life satisfaction, family structure, family affluence and gender differences in parent-child communication. Soc Indic Res. 2012;106(2):287-305.

16. Collishaw S, Gardner F, Maughan B, Scott J, Pickles A. Do historical changes in parent-child relationships explain increases in youth conduct problems? J Abnorm Child Psychol. 2012 Jan;40(1):119-32.

17. Sweeney MM. Remarriage and stepfamilies: strategic sites for family scholarship in the 21st century. J Marriage Fam. 2010;72(3):667-84.

18. Coleman M, Ganong L, Russell LT. Resilience in stepfamilies. In: Becvar DS, editor. Handbook of family resilience. New York: Springer; 2013. p. 85-103.

19. Hetherington EM, Kelly J. For better or for worse: divorce reconsidered. New York: W. W. Norton; 2002.

20. Capron C, Thérond C, Duyme M. Brief report: effect of menarcheal status and family structure on depressive symptoms and emotional/behavioural problems in young adolescent girls. J Adolesc. 2007 Feb;30(1):175-9.
21. Yuan ASV, Hamilton HA. Stepfather involvement and adolescent wellbeing: do mothers and nonresidential fathers matter? J Fam Issues. 2006;27(9):1191-213.

22. Bjarnason T, Bendtsen P, Arnarsson AM, Borup I, Iannotti RJ, Löfstedt P, et al. Life satisfaction among children in different family structures: A comparative study of 36 western societies. Child Soc. 2012;26(1):51-62.

23. Stewart SD. Brave new stepfamilies: diverse paths toward stepfamily living. Thousand Oaks: Sage Publications; 2006.

24. King V, Amato PR, Lindstrom R. Stepfather-adolescent relationship quality during the first year of transitioning to a stepfamily. J Marriage Fam. 2015 Oct;77(5):1179-89.

25. Schrodt P, Soliz J, Braithwaite DO. A social relations model of everyday talk and relational satisfaction in stepfamilies. Commun Monogr. 2008;75(2):190-217.

26. Baxter LA, Braithwaite DO, Bryant L, Wagner A. Stepchildren's perceptions of the contradictions in communication with stepparents. J Soc Pers Relat. 2004;21(4):447-67.

27. Jensen TM, Pace GT. Stepfather involvement and stepfather-child relationship quality: race and parental marital status as moderators. J Marital Fam Ther. 2016 Oct;42(4):659-72.

28. Ganong LH, Coleman M, Jamison T. Patterns of stepchild-stepparent relationship development. J Marriage Fam. 2011;73(2):396-413.

29. Le Poire BA. Family communication: nurturing and control in a changing world. Thousand Oaks: Sage Publications; 2005.

30. Inchley J, Currie D, Young T, Samdal O, Torsheim T, Augustson L, et al., editors. Growing up unequal: Gender and socioeconomic differences in young people's health and well-being. Health Behaviour in School-aged Children (HBSC) study: International report from the 2013/2014 survey. Copenhagen: WHO Regional Office for Europe; 2016.

31. Vokacova J, Badura P, Pavelka J, Kalman M, Hanus R. Brief report: Changes in parent-adolescent joint activities between 2002 and 2014 in the Czech Republic, Health Behaviour in School-aged Children (HBSC) study. J Adolesc. 2016 Aug;51:1-5.

32. Brannon L. Gender: Psychological perspectives. 6th ed. Oxford: Routledge; 2016.

33. Patterson JM. Integrating family resilience and family stress theory. J Marriage Fam. 2002;64(2):349-60.

34. Brooks F, Zaborskis A, Tabak I, Carmen Granado Alcón MD, Zemaitiene $\mathrm{N}$, de Roos S, et al. Trends in adolescents' perceived parental communication across 32 countries in Europe and North America from 2002 to 2010. Eur J Public Health. 2015 Apr;25 Suppl 2:46-50.

35. Dallago L, Santinello M. Communication in the family: working with one parent. Psicologia clinica dello sviluppo. 2006;10(2):241-62.

36. Kuntsche EN, Kuendig H. What is worse? A hierarchy of family-related risk factors predicting alcohol use in adolescence. Subst Use Misuse. 2006;41(1):71-86.

37. Jensen TM, Shafer K. Stepfamily functioning and closeness: children's views on second marriages and stepfather relationships. Soc Work. 2013 Apr;58(2):127-36.

38. King V, Thorsen ML, Amato PR. Factors associated with positive relationships between stepfathers and adolescent stepchildren. Soc Sci Res. 2014 Sep;47:16-29.

39. Zaborskis A, Zemaitiene N, Borup I, Kuntsche E, Moreno C. Family joint activities in a cross-national perspective. BMC Public Health. 2007 May 30;7(1):1-14.

40. Sweeting H. Our family, whose perspective? An investigation of children's family life and health. J Adolesc. 2001 Apr;24(2):229-50. 